\title{
Responses of Substrates and Salt Stress on Dracaena braunii to High Chloride lons Concentrations in Ornamental Hydro-culture
}

\author{
Jin Hee Ju', Hye Mi Son ${ }^{2}$, and Yong Han Yoon ${ }^{1 *}$ \\ ${ }^{1}$ Department of Green Technology Convergence, College of Science Technology, Konkuk University, Chungju 27478, South Korea \\ ${ }^{2}$ Department of Green Technology Convergence, Graduate School of Natural Science, Konkuk University, Chungju 27478, South Korea
}

\begin{abstract}
In order to determine the short-term impact induced by chloride ionic, $\mathrm{CaCl}_{2}$ was used to study the chloride ionic effects of salinity on substrate and growth of Dracacena braunii grown in ornamental hydro-culture. A distilled water (control) was enriched with 10, 20, 50,100 , and $150 \mathrm{~g} \cdot \mathrm{L}^{-1}$ of $\mathrm{CaCl}_{2}$, respectively. Before planting, acidity and electronic conductivity values remarkably increased with increasing concentration of $\mathrm{CaCl}_{2}$. However, 4 weeks after planting, acidity values decreased to a slightly acidic $\mathrm{pH}$, while there were not significant differences among electronic conductivity values obtained. Number of root, fresh weight, and total chlorophyll content were significantly decreased in response to $\mathrm{CaCl}_{2}$ concentration in comparison with control, whereas dry weight, water content, and color of stem were no significant effect of $\mathrm{CaCl}_{2}$ concentration less than $20 \mathrm{~g} \cdot \mathrm{L}^{-1}$. These results showed that initial $\mathrm{CaCl}_{2}$ concentrations above $20 \mathrm{~g} \cdot \mathrm{L}^{-1}$ is considered to be the threshold value that will sustain the Dracacena braunii in the growth condition and above which plant growth will be retarded.
\end{abstract}

Key words: calcium chloride, electronic conductivity, salt tolerant plant, total chlorophyll content

\section{I . Introduction}

Tap water is chlorinated at the final stage of water purification to disinfect toxic microorganisms. Since residual chlorine in water causes disgusting odors and bad water tastes, and increases risks of atopic dermatitis, congenital fever, eczema and allergic diseases such as asthma, the total residual chlorine in tap water is limited to $0.1 \sim 4.0 \mathrm{mg} \cdot \mathrm{L}^{-1}$ under the relevant regulations (Kim and Chung, 2012). Hydro-culture for ornamental plants using transparent containers can save labor costs for watering, has no risk of drought damage and thus has become more popular among the general public (Jang et al., 2009). It is true that hydro-culture media are less prone to damage from salination than soil culture. Given that it is difficult to continue to supply tap water to and drain it from hydro-culture media, however, accumulated residual chlorine in media can have a

Received on December 19, 2016. Revised on January 26, 2017.

Accepted on March 15, 2017.

*Comesponding author: yonghan7204@kku.ac.kr

This research was supported by Basic Science Research Program through the National Research Foundation of Korea (NRF) funded by the Ministry of Science, ICT \& Future Planning (2015-A002-0095). negative impact on plants.

The results of a study on the growth and development of Eichhornia crassipes depending on the concentration of chloride ions (El-Gendy et al., 2005) showed that it withered at the concentration of $3 \mathrm{~g} \cdot \mathrm{L}^{-1}$ or higher on the $18^{\text {th }}$ day, and at the concentration of $5 \mathrm{~g} \cdot \mathrm{L}^{-1}$ or higher on the $3^{\text {rd }}$ day. Since the study mainly focused on aquatic plants, it is necessary to build data on a wider range of species.

Dracaena braunii, a species of the genus Dracaena, can be grown well both in soil and water culture. This house plant is a native North African species, and grows over $1.5 \mathrm{~m}$ outdoors, and as high as $1.0 \mathrm{~m}$ indoors. Dracaena braunii grows better in soil culture than in water culture, but many people grow it in hydro-culture indoors for ornamental purposes. However, there is no study on changes in conditions of hydro-culture media and responses to salt stress on Dracaena braunii used for indoor ornamental purposes depending on the concentration of chloride ions.

Against this backdrop, this study aimed to observe changes in the conditions of hydro-culture media and responses to salt stress using Dracaena braunii depending on the treatment of 
high chloride ions, and to suggest indicators that can be used to identify threshold and damage levels.

\section{Materials and Methods}

\section{Materials}

In this study, $250 \mathrm{~mL}$ transparent conical flasks were used in hydro-culture (AO205, Dongsung Science, Korea). To treat water with chloride ions, calcium chloride $74 \%$ powder $\left(\mathrm{CaCl}_{2}\right.$, Oriental Chemical Industries, Korea) was used. Dracaena braunii of the relatively similar shape and size (the length of stem, $15 \pm 2 \mathrm{~cm}$ ) was bought at Yangchon Flower Shop located in Seowon-gu, Cheongju City.

\section{Methods}

This experiment was conducted in a growth chamber for 4 weeks from February 12 to March 12, 2016. Considering the growth and development conditions of Dracaena braunii, internal environmental conditions were set as follows: temperature, $23 \pm 1{ }^{\circ} \mathrm{C}$; relative humidity, $70 \pm 3 \%$; light intensity, $200 \mu \mathrm{mol} \cdot \mathrm{m}^{-2} \cdot \mathrm{s}^{-1}$; and day length, $14 / 10$ (light/shade) hours.

In this study, the concentration of chloride ions generated by calcium chloride for ornamental hydro-culture was set to be high in order to suggest indicators of damage levels based on the threshold level and responses of Dracaena braunii to salt stress. Referring to the results of earlier studies on the treatment concentration of chloride ions (Yang et al., 2009; Dudley et al., 2014), 0 (CON), 10 (C10), 20 (C20), 50 (C50), 100 (C100), and $150 \mathrm{~g}(\mathrm{C} 150)$ of calcium chloride were added to each liter of single distilled water to make a total of 6 treated plots as follows: $0,70,140,350,700$, and 1,050 $\mathrm{mM}$. The actual concentrations of chloride ions $\left(\mathrm{Cl}^{-}\right)$were $0,4.72,9.44,23.6$, 47.2 , and $70.8 \mathrm{~g} \cdot \mathrm{L}^{-1}$. Each solution was divided into conical flasks by $100 \mathrm{~mL}$, and the roots of Dracaena braunii were safely placed on the bottom of the containers. A completely randomized design was used with 10 replicate pens per treated plot.

Changes in the conditions of media before and after planting Dracaena braunii were observed mainly focusing on acidity and electrical conductivity. After filtering each solution through a filter paper, acidity and electrical conductivity were measured using a pH meter (86505, AZ, China), and a EC meter (CON510, EUTECH instruments, Singapore) respectively.

After 4 weeks, the responses of each treated plot to salt stress were measured focusing on the number of roots, the fresh and dry weight of stems, water content, and stem color. The number of roots that were over $1 \mathrm{~cm}$ long was counted with the naked eyes, and the fresh and dry weight of each sample were measured by dividing it into the aerial and underground parts and drying it in a dry oven (C-DF, CHANGSHIN Sci Co, Korea) at $70^{\circ} \mathrm{C}$ for 48 hours. The water content of plant bodies was calculated using the following equation: water content $=$ fresh weight (g) - dry weight $(\mathrm{g}) /$ dry weight $(\mathrm{g}) \times 100 \%$. The color values of stems were measured using a color meter (CR-10, Minlota, Japan) as follows: Hunter L* (darknessbrightness); $\mathrm{a}^{*}$ (green-red); and b* (blue-yellow). To analyze the total chlorophyll content, stems from the plant body of each treated plot were grinded, and $50 \mathrm{~mL}$ of $80 \%$ acetone solution per $1 \mathrm{~g}$ of the grinded stems was used for extraction. The extracted liquid was filtered through a filter paper (Watman No. 2). The absorbance of the extracted liquid was measured at $645 \mathrm{~nm}$ and $663 \mathrm{~nm}$ using a spectrophotometer (SpectraMaxM2, Molecular Devices, USA), and the total chlorophyll was calculated based on the method suggested by Kanawapee et al.(2012). The total chlorophyll values were marked as $\mathrm{mg} \cdot \mathrm{g}^{-1}$ FW.

The measured data were statistically analyzed using SPSS Ver. 12.0 (SPSS Inc., USA), and their significance was tested using Duncan's multiple range test at the 5\% significance level.

\section{Results and Discussion}

\section{Conditions of hydro-culture media}

The acidity level of media before planting Dracaena braunii was $6.39 \sim 10.3$, but after 4 weeks after planting the level was reduced to $5.95 \sim 6.38$, changing from alkaline to neutral or slightly acidic (Fig. 1). In detail, the acidity level of the control plot and the five treated plots $(\mathrm{C} 10, \mathrm{C} 20, \mathrm{C} 50, \mathrm{C} 100$, and $\mathrm{C} 150$ ) before planting was gradually increased as follows: $7.91,6.39,8.44,9.82,10.21$, and 10.38 , but the level after 4 weeks after planting was reduced to $6.38,6.16,6.29,5.96$, 


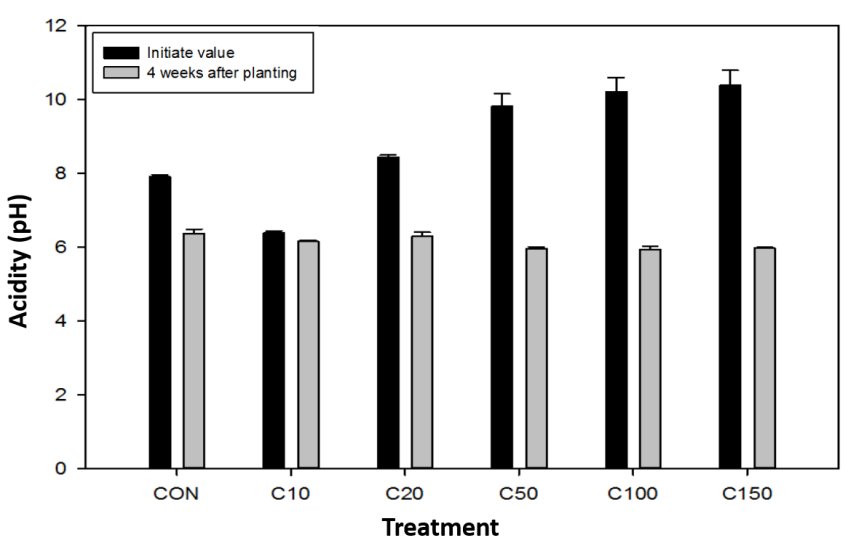

Fig. 1. Changes in acidity of media grown Dracaena braunii for 4 weeks after planting as affected by different calcium chlorid concentrations in ornamental hydro-culture. Vertical bars represent standard error of the mean $(n=10)$. CON; Control, C10; $\mathrm{CaCl}_{2} 10 \mathrm{~g} \cdot \mathrm{L}^{-1}, \mathrm{C} 20 ; \mathrm{CaCl}_{2} 20 \mathrm{~g} \cdot \mathrm{L}^{-1}$, $\mathrm{C} 50 ; \mathrm{CaCl}_{2} 50 \mathrm{~g} \cdot \mathrm{L}^{-1}, \mathrm{C} 100 ; \mathrm{CaCl}_{2} 100 \mathrm{~g} \cdot \mathrm{L}^{-1}, \mathrm{C} 150 ; \mathrm{CaCl}_{2} 150 \mathrm{~g} \cdot \mathrm{L}^{-1}$.

5.95, and 5.97 respectively, showing neutral or slightly acidic properties. Acidity in hydro-culture is known to affect the absorption of inorganic ions such as positive and negative ions, and also known to significantly change the balance within a medium (Soh et al., 2015). Calcium chloride, as an ionic compound, is soluble and ionized in water into $\mathrm{Ca}^{2+}$ and $2 \mathrm{Cl}^{-}$. Chloride ions $\left(\mathrm{Cl}^{-}\right)$are combined with hydrogen ions $\left(\mathrm{H}^{+}\right)$in water to produce hydrogen chloride, that is, strongly acidic hydrochloric acid $(\mathrm{HCl})$. In particular, the higher the acidity level, the more positive ions $\left(\mathrm{Ca}^{2+}\right)$ are produced than negative ions $\left(2 \mathrm{Cl}^{-}\right)$(Soh et al., 2015), and the acidity range is found to be decreased from $6.39 \sim 10.3$ to $5.95 \sim 6.38$ due to this reason. Meanwhile, chlorine $\left(\mathrm{Cl}_{2}\right)$ in water exists in the form of hypochlorous acid $(\mathrm{HClO})$ or hypochlorite ion $\left(\mathrm{ClO}^{-}\right)$depending on the acidity level of water. At a low acidity level, $\mathrm{HClO}$ is produced more than $\mathrm{ClO}^{-}$, while at a high acidity level, $\mathrm{ClO}^{-}$is produced more. Considering that chlorine exists in the form of $\mathrm{Cl}_{2}$ at acidity 5 or lower (Kim and Chung, 2012), chloride ions in media seem to exist mainly in the form of $\mathrm{ClO}^{-}$, which could have a negative impact on the growth and development of plants from a short-term perspective.

As the concentration of chloride ions increased, electrical conductivity clearly increased, but the difference between before and after planting was not significant (Fig. 2). Before planting, the electrical conductivity level of the control plot and the five treated plots $(\mathrm{C} 10, \mathrm{C} 20, \mathrm{C} 50, \mathrm{C} 100$, and C150)

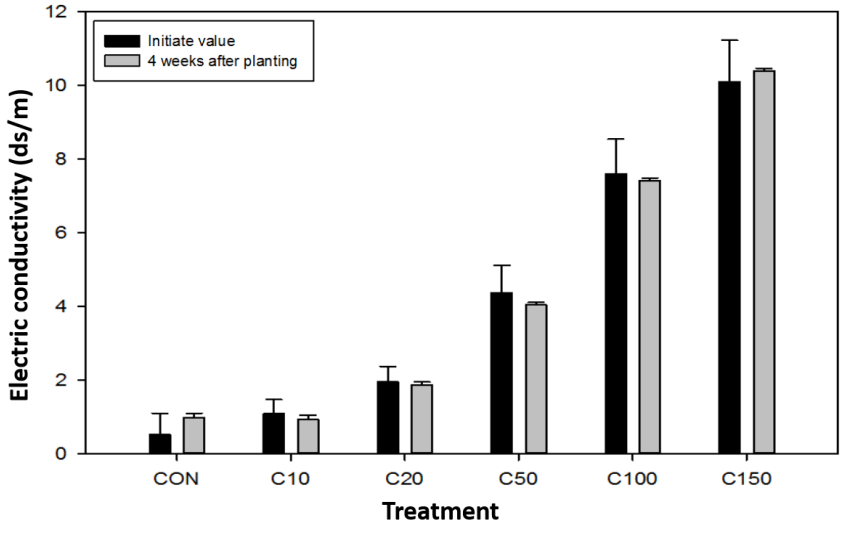

Fig. 2. Changes in electric conductivity of media grown Dracaena braunii for 4 weeks after planting as affected by different calcium chloride concentrations in ornamental hydro-culture. Vertical bars represent standard error of the mean $(n=10)$. CON; Control, $\mathrm{C10} ; \mathrm{CaCl}_{2} 10 \mathrm{~g} \cdot \mathrm{L}^{-1}$, $\mathrm{C} 20 ; \mathrm{CaCl}_{2} 20 \mathrm{~g} \cdot \mathrm{L}^{-1}, \mathrm{C} 50 ; \mathrm{CaCl}_{2} 50 \mathrm{~g} \cdot \mathrm{L}^{-1}, \mathrm{C} 100 ; \mathrm{CaCl}_{2} 100 \mathrm{~g} \cdot \mathrm{L}^{-1}, \mathrm{C} 150$; $\mathrm{CaCl}_{2} 150 \mathrm{~g} \cdot \mathrm{L}^{-1}$.

were $0.52,1.09,1.95,4.36,7.60$, and $10.09 \mathrm{dS} \cdot \mathrm{m}^{-1}$ respectively, and after 4 weeks after planting, the level was $0.99,0.93,1.87$, $4.04,7.42$, and $10.39 \mathrm{dS} \cdot \mathrm{m}^{-1}$ respectively. The level of the control plot increased, while the level of the $\mathrm{C} 10 \sim \mathrm{C} 100$ treated plots decreased. That of $\mathrm{C} 150$ increased, but the difference between before and after planting was not significant. Electrical conductivity is known as an indicator that comprehensively shows the concentration levels of contained ions and salts by measuring the levels of ionic components and impurities (Kang and Ju, 2013). Electrical conductivity is also reported to be closely related to the concentration of chloride ions in water (Baek et al., 2014). In hydro-culture, electrical conductivity $1.0 \mathrm{dS} \cdot \mathrm{m}^{-1}$ is assumed to be the lowest salinity, and Yamazaki nutrient solution used to grow lettuce (Yamazaki, 1982 ) is controlled at $1.2 \mathrm{dS} \cdot \mathrm{m}^{-1}$. Given that, Dracaena braunii grown in hydro-culture for ornamental purposes is believed to be seriously underdeveloped in the $\mathrm{C} 20$ and higher-concentration plots at electrical conductivity of $1.95 \mathrm{dS} \cdot \mathrm{m}^{-1}$ or higher.

\section{Responses to salt stress}

The responses of Dracaena braunii to salt stress depending on the level of chloride ion treatment were shown in Table 1. In terms of the number of roots, there was no significant difference among the treated plots except the control plot. The higher the concentration of calcium chloride treatment, the 
Table 1. Number of root, fresh weight, dry weight, and water content of Dracaena braunii as affected by different calcium chloride concentrations in ornamental hydro-culture.

\begin{tabular}{lcccc}
\hline \multicolumn{1}{c}{ Treatments } & No. of root & Fresh weight (g/plant) & Dry weight (g/plant) & Water content (\%) \\
\hline $\mathrm{CON}^{\mathrm{y}}$ & $1.2 \mathrm{a}^{\mathrm{z}}$ & $18.12 \mathrm{a}$ & $3.88 \mathrm{a}$ & $3.96 \mathrm{a}$ \\
$\mathrm{C} 10$ & - & $16.53 \mathrm{ab}$ & $3.42 \mathrm{a}$ & $4.00 \mathrm{a}$ \\
$\mathrm{C} 20$ & - & $15.72 \mathrm{bc}$ & $3.36 \mathrm{a}$ & $3.76 \mathrm{a}$ \\
$\mathrm{C} 50$ & - & $14.06 \mathrm{c}$ & $3.15 \mathrm{a}$ & $3.61 \mathrm{ab}$ \\
$\mathrm{C} 100$ & - & $13.86 \mathrm{c}$ & $3.81 \mathrm{a}$ & $2.65 \mathrm{bc}$ \\
$\mathrm{C} 150$ & - & $13.86 \mathrm{c}$ & $4.18 \mathrm{a}$ & $2.37 \mathrm{c}$ \\
\hline
\end{tabular}

${ }^{7}$ Different letters within columns indicate significant differences based on Duncan's multiple range test at $p=0.05(\mathrm{n}=10)$.

${ }^{\mathrm{y}} \mathrm{CON} ;$ Control, $\mathrm{C} 10 ; \mathrm{CaCl}_{2} 10 \mathrm{~g} \cdot \mathrm{L}^{-1}, \mathrm{C} 20 ; \mathrm{CaCl}_{2} 20 \mathrm{~g} \cdot \mathrm{L}^{-1}, \mathrm{C} 50 ; \mathrm{CaCl}_{2} 50 \mathrm{~g} \cdot \mathrm{L}^{-1}, \mathrm{C} 100 ; \mathrm{CaCl}_{2} 100 \mathrm{~g} \cdot \mathrm{L}^{-1}, \mathrm{C} 150 ; \mathrm{CaCl}_{2} 150 \mathrm{~g} \cdot \mathrm{L}^{-1}$.

lower the fresh weight of Dracaena braunii. However, there was no clear difference in the dry weight of Dracaena braunii, and the water content of the plant body gradually decreased. In detail, the fresh weight of the control plot and C10, C20, C50, C100, and C150 treated plots was 18.12, 16.53, 15.72, 14.06, 13.86 , and $13.86 \mathrm{~g}$ respectively, showing a statistically significant decrease. The dry weight of the plots was $3.88,3.42,3.36$, $3.15,3.81$, and $4.18 \mathrm{~g}$ respectively, showing no significant pattern. The water content of the plant was 3.96, 4.00, 3.76, $3.61,2.65$, and $2.37 \mathrm{~g}$ respectively, showing a statistically significant decrease at the high concentration of calcium chloride $\left(20 \mathrm{~g} \cdot \mathrm{L}^{-1}\right.$ or higher). These results are in line with the results of an earlier study (Dolatabadian et al., 2011) that indicated that salt stress significantly decreased the weight of the aerial and underground parts, and the total biomass (Dolatabadian et al., 2011). The results seem to be closely related to salt stresses caused by a high concentration of chloride ions such as the decrease in the height and the biomass of the aerial and underground parts of the plant (Borgognone et al., 2014; Patel et al., 2010). In a study on Suaeda salsa, it was reported that the length of the plant, the number of branches, the length of branches, and the diameter of stems were significantly decreased as the concentration of chloride ions increases (Guan et al., 2011), and that the length, fresh weight, production and biomass of Foeniculum vulgare were also affected negatively by chloride ions (Semiz et al., 2012). Meanwhile, chloride ions $\left(\mathrm{Cl}^{-}\right)$in soil is recognized as one of the key contributors to the decrease in the growth and development, and production of plants, and the critical concentration level of chloride ions is found to be $490 \mathrm{mg} \cdot \mathrm{kg}^{-1}$ at which the growth and development, and production of plants decreased by $10 \%$ (Dang et al., 2008). In addition, the critical level of species that are sensitive to chloride ions is $4 \sim 7 \mathrm{mg} \cdot \mathrm{g}^{-1}$, and that of those that are tolerant of chloride ions is $15 \sim 50 \mathrm{mg} \cdot \mathrm{g}^{-1}$ (Xu et al., 2000; White and Broadley, 2001). Considering this, it can be inferred that Dracaena braunii grown in hydro-culture is relatively tolerant of chloride ions, but, taking the short-term responses to salt stress into consideration, it is believed that Dracaena braunii is unable to survive at the concentration of chloride ions of $9.44 \mathrm{~g} \cdot \mathrm{L}^{-1}$ or higher.

To visually observe the responses of Dracaena braunii to salt stress, the color of its stems was measured. The higher the concentration of chloride ions, the brighter the overall color of its stems, and the relatively clearer the yellow etiolation (Table 2, Fig. 3). In detail, the L value gradually increased to 72.79 $(\mathrm{C} 150)$ at $51.99(\mathrm{CON})$ and turned brighter, and the a value was $-0.89(\mathrm{C} 150)$ at $-18.70(\mathrm{CON})$. The b value was 40.13 $(\mathrm{C} 150)$ at $33.66(\mathrm{CON})$, indicating that red and yellow were more clearly expressed than green and blue respectively. There was almost no change in the color of stems in the control plot and the $\mathrm{C} 10$ treated plot added with calcium chloride $10 \mathrm{~g} \cdot \mathrm{L}^{-1}$. From the C20 treated plot, the end of stems started to turn yellow, which can be recognized as the boundary concentration that starts to show color difference. However, the difference was not clear enough, and thus it is necessary to conduct further studies on the continuum between media and plant.

The total chlorophyll content was clearly reduced as the concentration of chloride ions increased. That is, the total chlorophyll content of the control plot, and the $\mathrm{C} 10, \mathrm{C} 20, \mathrm{C} 50$, $\mathrm{C} 100$, and $\mathrm{C} 150$ treated plots was 2.134, 1.113, 0.956, 0.623, 
Jin Hee Ju, Hye Mi Son, and Yong Han Yoon

Table 2. Stem color and total chlorophyll content of Dracaena braunii as affected by different calcium chloride concentrations in ornamental hydro-culture.

\begin{tabular}{lcccc}
\hline \multirow{2}{*}{ Treatments } & \multicolumn{3}{c}{ Stem color (chromaticity) } & $\begin{array}{c}\text { Total chlorophyll content } \\
\left(\mathrm{mg} \cdot \mathrm{g}^{-1} \mathrm{FW}\right)\end{array}$ \\
\cline { 2 - 4 } $\mathrm{CON}^{\mathrm{y}}$ & $\mathrm{L}^{*^{\mathrm{x}}}$ & $\mathrm{a}^{*}$ & $\mathrm{~b}^{*}$ & $2.134 \mathrm{a}$ \\
$\mathrm{C} 10$ & $51.99 \mathrm{~d}^{\mathrm{z}}$ & $-18.70 \mathrm{c}$ & $33.66 \mathrm{~b}$ & $1.113 \mathrm{~b}$ \\
$\mathrm{C} 20$ & $54.59 \mathrm{~d}$ & $-17.66 \mathrm{c}$ & $34.22 \mathrm{~b}$ & $0.956 \mathrm{c}$ \\
$\mathrm{C} 50$ & $62.90 \mathrm{c}$ & $-16.76 \mathrm{c}$ & $35.67 \mathrm{~b}$ & $0.623 \mathrm{~d}$ \\
$\mathrm{C} 100$ & $68.01 \mathrm{~b}$ & $-9.93 \mathrm{~b}$ & $39.89 \mathrm{a}$ & $0.406 \mathrm{e}$ \\
$\mathrm{C} 150$ & $72.98 \mathrm{a}$ & $-1.31 \mathrm{a}$ & $40.55 \mathrm{a}$ & $0.274 \mathrm{f}$ \\
\hline
\end{tabular}

${ }^{\mathrm{z}}$ Different letters within columns indicate significant differences based on Duncan's multiple range test at $p=0.05(\mathrm{n}=10)$.

${ }^{\mathrm{y}} \mathrm{CON}$; Control, $\mathrm{C} 10 ; \mathrm{CaCl}_{2} 10 \mathrm{~g} \cdot \mathrm{L}^{-1}, \mathrm{C} 20 ; \mathrm{CaCl}_{2} 20 \mathrm{~g} \cdot \mathrm{L}^{-1}, \mathrm{C} 50 ; \mathrm{CaCl}_{2} 50 \mathrm{~g} \cdot \mathrm{L}^{-1}, \mathrm{C} 100 ; \mathrm{CaCl}_{2} 100 \mathrm{~g} \cdot \mathrm{L}^{-1}, \mathrm{C} 150 ; \mathrm{CaCl}_{2} 150 \mathrm{~g} \cdot \mathrm{L}^{-1}$.

${ }^{\mathrm{x}} \mathrm{L}$ indicates the brightness and ranges from 0 to 100 , a and $\mathrm{b}$ range from -100 to 100 , where negative a indicates green, positive a indicates red, negative $\mathrm{b}$ indicates blue and positive $\mathrm{b}$ indicates yellow.

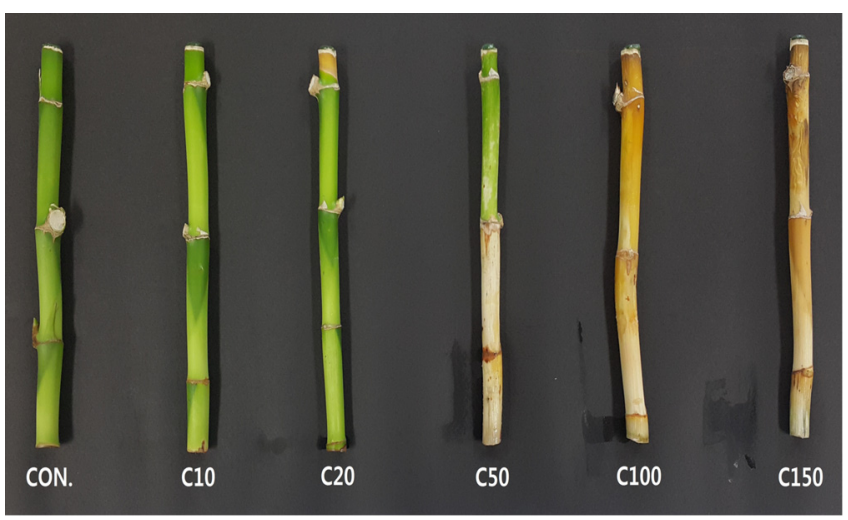

Fig. 3. Effect of calcium chloride concentration on the stem color of Dracaena braunii. From left to right $\mathrm{CON}$; Control, $\mathrm{C} 10 ; \mathrm{CaCl}_{2} 10 \mathrm{~g} \cdot \mathrm{L}^{-1}, \mathrm{C} 20 ; \mathrm{CaCl}_{2}$ $20 \mathrm{~g} \cdot \mathrm{L}^{-1}, \mathrm{C} 50 ; \mathrm{CaCl}_{2} 50 \mathrm{~g} \cdot \mathrm{L}^{-1}, \mathrm{C} 100 ; \mathrm{CaCl}_{2} 100 \mathrm{~g} \cdot \mathrm{L}^{-1}, \mathrm{C} 150 ; \mathrm{CaCl}_{2} 150$ $g \cdot L^{-1}$.

0.406 , and $0.274 \mathrm{mg} \cdot \mathrm{g}^{-1} \mathrm{FW}$ respectively, showing a statistically significant decrease. Saha et al. (2011) found that at a higher concentration of chloride ions, the total chlorophyll content of Vigna radiata decreased by $31 \%$ from that of the control plot. In addition, when cucumber was grown in media treated with 2,3 and $5 \mathrm{dS} \cdot \mathrm{m}^{-1}$ of salt, the total chlorophyll content was reduced by 12,21 and $30 \%$ respectively from the content of the control plot (Khan et al., 2013). There are several reasons behind these results, and one of them is known to be related to damage to cell membrane (Mane et al., 2010). It was also found that chlorine ions $\left(\mathrm{Cl}^{-}\right)$interfere with the production of chlorophyll, and is the main contributor to chlorosis (Tavakkoli et al., 2011). Considering this, the concentration of chloride ions beyond the tolerance level seems to be closely related to the decrease in the total chlorophyll content. Meanwhile, it was also reported that the chlorophyll content of costal plants such as Camellia japonica, Ardisia japonica and Aster sphathulifolius increased when the concentration of salt in soil in a reclaimed land was $0.32 \%$ (Lee et al., 2008). Eugenia myrtifolia, a Mediterranean plant, tends to increase its chlorophyll content to protect its photosynthesis mechanism from salt stress (Acosta-Motos et al., 2015). Rosa rubiginosa treated with calcium chloride $\left(\mathrm{CaCl}_{2}\right)$ was deformed more visually than one that was treated with sodium chloride $(\mathrm{NaCl})$ (Tomasz et al., 2017). These results indicate that the chlorophyll content of plant can be used as an indicator to predict salt stress and select salt tolerant plants.

\section{Conclusions}

This study aimed to observe changes in the conditions of hydro-culture media and responses of Dracaena braunii to salt stress depending on the concentration level of chloride ions, and suggest indicators that can be used to identify threshold and damage levels. The conditions of media were observed focusing on changes in acidity and electrical conductivity before and after planting, the number of roots, the fresh and dry weight of stems, water content, stem color, and the total chlorophyll content.

The acidity level of ornamental hydro-culture media treated with chloride ions before planting was $6.39 \sim 10.3$, while that of media after 4 weeks after planting was $5.95 \sim 6.38$, changing 
from alkaline to neutral or slightly acidic. The higher the concentration of chlorine ions, the higher the growth rate of electronic conductivity, but there was no significant difference between before and after planting. In terms of the number of roots, there was no significant difference among the treated plots except the control plot. The higher the concentration of calcium chloride treatment, the lower the fresh weight, but there was no clear change in the dry weight. The water content of the plant gradually decreased. The higher the concentration of treatment, the more clearer the etiolation symptom that changes from green to yellow. The total chlorophyll content was significantly reduced.

In summary, the higher the concentration of chloride ion treatment, the higher the levels of acidity and electrical conductivity. When conditions before and after planting were compared, the acidity condition in media changed from alkaline to slightly acidic, but there was no significant change in electrical conductivity. In terms of responses to salt stress, there was no clear difference in the dry weight, water content and stem color among the treated plots lower than C20. On the other hand, the number of roots, the fresh weight, and the total chlorophyll content showed clear differences, and thus, they can be used as indicators to diagnose salt stress. Based on the results, the threshold level of chlorine of Dracaena braunii grown in hydro-culture for ornamental purposes was found to be calcium chloride $20 \mathrm{~g} \cdot \mathrm{L}^{-1}$. It is necessary to conduct follow-up studies to understand complex relationships such as continuum between medium and plant body in the treated plots lower than C20 from a long-term perspective.

\section{References}

Acosta-Motos, J.R., P. Diaz-Vivancos, S. Álvarez, N, Fernández-García, M.J. Sanchez-Blanco, and J.A. Hernández. 2015. Physiological and biochemical mechanisms of the ornamental Eugenia myrtifolia L. plants for coping with $\mathrm{NaCl}$ stress. Planta 242(4):829-846.

Baek, M.J., T.J. Yoon, D.G. Kim, C.Y. Lee, K.J. Cho, and Y.J. Bae. 2014. Effects of road deicer runoff on benthic macroinvertebrate communities in Korean freshwaters with toxicity tests of calcium chloride (CaCl2). Water Air Soil Pollut. 225(6):1961-1966.

Borgognone, D., M. Cardarelli, L. Lucini, and G. Colla. 2014. Dose $\mathrm{CaCl}_{2}$ play a role in improving biomass yield and quality of cardoon grown in a floating system under saline condition? HortScience 49(12):1523-1528.
Dang Y.P., R.C. Dalal, D.G. Mayer, M. McDonald, R. Routely, G.D. Schwenke, S.R. Buck, I.G. Daniells, D.K. Singh, W. Manning, and N. Ferguson. 2008. High subsoil chloride concentrations reduce soil water extraction and crop yield on Vertisols in northeastern Australia. Crop Pasture Sci. 59(4):321-330.

Dolatabadian, A., S.A.M.M. Sanavy, and F. Ghanati. 2011. Effect of salinity on growth, xylem structure and anatomical characteristics of soybean. Notulae Sci. Biol. 3(1):41-45.

Dudley, M.M., W.R. Jacobi, and C.S. Brown. 2014. Roadway deicer effects on the germination of native grasses and forbs. Water Air Soil Pollut. 225:1984.

El-Gendy, A.S., N. Biswas, and J.K. Bewtra. 2005. A floating aquatic system employing water hyacinth for municipal landfill leachate treatment: effect of leachate characteristics on the plant growth. J. Environ. Eng. Sci. 4(4):227-240.

Guan, B., J. Yu, X. Chen, W. Xie, and Z. Lu. 2011. Effects of salt stress and nitrogen application on growth and ion accumulation of Suaeda salsa plants. In Remote Sens. Environ. Transport. Engin. 2011 International Conference on (pp. 8268-8272). IEEE.

Jang, H.S., S.G. Lee, J.H. Moon, and C.H. Park. 2009. Effect of applied substrates on foliage growth in hydro-culture. J. Bio-Environ. Control 18(4):460-467.

Kanawapee, N., J. Sanitchon, W. Lontom, and P. Threerakulpisut. 2012. Evaluation of salt tolerance at the seedling stage in rice genotypes by growth performance, ion accumulation, proline and chlorophyll content. Plant Soil 358(1-2):235-249.

Kang, K.C. and J.H. Ju. 2013. Growth responses of Epipremnum aureum as affected by different water and activated carbon ratios in ornamental hydro-culture. J. Kor. Soc. People Plants Environ. 16(6):377-382.

Khan, M.M., R.S.M. Al-Mas'oudi, F. Al-Said, and I. Khan. 2013. Salinity effects on growth, electrolyte leakage, chlorophyll content and lipid peroxidation in cucumber (Cucumis sativus L.). 2013 Int. Proc. Chem. Biol. Environ. Eng. 55(6):28-32.

Kim, H.W. and N.Y. Chung. 2012. Effectiveness of the electrochemical sensor for the free chlorine measurement. J. Korean Soc. Manuf. Technol. Eng. 21(5):720-725.

Lee, J.J., S.G. Han, C.H. Kang, H.K. Cho, J.S. Jeong, and K.B. Lee. 2008. Adaptability of saline-tolerant plants selected indoors at reclaimed land. Proc. 2008 Fall Symposium Korean J. Plant Resour. p. 111.

Mane, A.V., B.A. Karadge, and J.S. Samant. 2010. Salinity induced changes in photosynthetic pigments and polyphenols of Cymbopogon Nardus (L.) Rendle. J. Chem. Pharm. Res. 2(3):338-347.

Nath Pandey, A., I. Bhushan Pandey, N. Sundarjibhai Panchal, and A. Dayabhai Patel. 2010. Growth, water status and nutrient accumulation of seedlings of Jatropha curcas L. (Euphorbiaceae) in response to soil salinity. In Anales de biología. Murcia: Universidad de Murcia, Servicio de Publicaciones.

Saha, P., P. Chatterjee, and A.K. Biswas. 2010. NaCl pretreatment alleviates salt stress by enhancement of antioxidant defense system and osmolyte accumulation in mungbean (Vigna radiata L.Wilczek). Indian J. Exp. Biol. 48(6):593-600. 
Semiz, G.D., A. Ünlukara, E. Yurtseven, D.L. Suarez, and I. Telci. 2012. Salinity impact on yield, water use, mineral and essential oil content of fennel (Foeniculum vulgare Mill.). J. Agric. Sci. 18:177-186.

Soh, J.W., S.Y. Soh, and S.Y. Nam. 2015. pH variance model depending on phosphate ion form. Korean J. Hortic. Sci. Technol. 33(6): 854-859.

Tavakkoli, E., F. Fatehi, S. Coventry, P. Rengasamy, and G.K. McDonald. 2011. Additive effects of $\mathrm{Na}+$ and $\mathrm{Cl}-$ ions on barley growth under salinity stress. J. Exp. Bot. 62(6):2189-2203.

Tomasz, H., S. Boena, H. Katarzyna, and N. Krzysztof. 2017. Phy- siological responses of Rosa rubiginosa to saline environment. Water Air Soil Pollut. 228(2):81.

White, P.J. and M.R. Broadley. 2001. Chloride in soils and its uptake and movement within the plant: a review. Ann. Bot. 88(6): 967-988.

Xu, G., H. Magen, J. Tarchitzky, and U. Kafkafi. 2000. Advances in chloride nutrition of plants. Adv. Agron. 68:97-150.

Yang, H., Z. Huang, C.C. Baskin, J.M. Baskin, Z. Cao, X. Zhu, and M. Dong. 2009. Response of caryopsis germination, early seedling growth and ramet clonal growth of Bromus inermis to soil salinity. Plant Soil 316(1):265-275. 
